\title{
Development of liaison psychiatry
}

\author{
Real expansion or a bubble that is about to burst?
}

\author{
E. Guthrie
}

\begin{abstract}
A survey was undertaken to establish the current state of liaison psychiatry in England, Scottand and Wales. Eighty-six consultants were identified who carry out specific work in liaison psychlatiry, 43 of these consultants hold either full-time or half-time posts in liaison. Sixteen new posts in liaison (full-time equivalent (FTE) or half-time equivalent (HIE)) have been created in the past two years. Half of these were entirely new posts and half hove been created by consultants already in a general peychiatry post renegotiating their contracts. Some specialist registrar schemes have no training slots in liaison peychiatiy and others have training stots in liaison poychiatry which are supervised by a trainer who is not in a FIE/HTE llaison post. A national database is required to track expansion in liaison psychiatry and training at speciallst registrar level needs to be developed.
\end{abstract}

Liaison psychiatry, together with rehabiliation psychiatry, has recently become a section of the Royal College of Psychiatrists, within the speciality of general psychiatry. The Royal College of Psychiatrists' report, Mental Health of the Nation recommends 0.4 FTE (full-time equivalent) consultants in liaison psychiatry per 100000 population. In practice, this translates into a minimum of a half-time consultant liaison psychiatrist, as part of a multi-disciplinary team, for every district general hospital (House \& Hodgson, 1994). Teaching hospitals require greater input.

The last survey of the state of liaison psychiatry in the UK (Mayou et al, 1990) found that out of 52 districts, 27 had an identifiable service. although in many instances this amounted to an emergency psychiatric service for the assessment of deliberate self-harm (DSH).

Liaison psychiatry is primarily concerned with the detection and treatment of psychiatric disorder within the general hospital (medical) setting. In addition to patients with overt psychiatric disorder (e.g. DSH), liaison psychiatry should involve the treatment of patients with more complex disorders (e.g. psychiatric reaction to physical illness or somatic presentation of psychological disorder) who often go undetected and untreated. General psychiatrists rarely see such patients and do not have the knowledge or skills base to treat and manage them appropriately. True liaison psychiatry services should, therefore, consist of more than solely an assessment service for DSH.

It is very difficult to gain accurate information concerning the number of general hospital liaison psychiatry services in the UK or the state of training in liaison psychiatry. The ambiguity implied in the term, 'liaison' has not helped and often leads to misunderstanding, with a variety of non-general hospital services being termed 'liaison psychiatry' if they span different areas of work within psychiatry directorates. There is no central database for liaison psychiatry and general manpower figures are inaccurate. The 1995 Annual Census for Psychiatric Staffing (Royal College of Psychiatrists, 1996) only recorded 17 consultant posts (either full-time equivalent (FTE) or half-time equivalent (HTE)) in Great Britain.

In order to try to gain a more accurate picture of the current state of liaison psychiatry in England. Scotland and Wales, the former liaison group (now section) of the Royal College of Psychiatrists decided to carry out a national survey. This coincided with a wish from the General and Old Age Specialty Advisory Committee to ascertain more information concerning the state of higher training in liaison psychiatry in the UK.

\section{Method}

The groups surveyed were: regional representatives in liaison psychiatry; known consultants in liaison psychiatry: consultants who attended the last three residential conferences in liaison psychiatry organised by the Royal College of Psychiatrists; and all senior registrar/specialist registrar scheme organisers. The survey was conducted during September 1996. Supplementary information was gathered over the following three months.

Information was collected on: the number of consultants undertaking specific sessions in liaison psychiatry (general psychiatry consultants whose sole 'liaison' work was DSH were excluded), the number of sessions worked and 
the type of liaison work undertaken. The number of specialist registrar training slots in liaison psychiatry for each scheme were counted, and details were collected about the specialist registrar trainer.

\section{Findings}

Eighty-six consultants were identified who carried out specific work in liaison psychiatry in addition to any DSH commitments. Fortythree of these held either FTE or HTE posts. Twenty-three liaison psychiatrists had academic posts: two eight-session posts, $12 \mathrm{HTE}$, one three-session post and the rest 1-2 sessions. Table 1 gives the location of posts, by region or major city for England, Scotland and Wales. Not surprisingly, London had over one-third of all FTE or HTE posts. Northern Region and Aberdeen had no FTE or HTE post in liaison psychiatry although Aberdeen had recently advertised a HTE post in liaison psychiatry which was not filled, and Northern Region have plans for a FTE post in liaison psychiatry in the near future, and a HTE post is about to be established.

Out of the forty-three consultants in FTE or HTE posts in liaison psychiatry, 16 had acquired their positions within the last two years. This means that the number of liaison psychiatrists in FTE/HTE posts has almost doubled over this period. Of the 16 new FTE/HTE consultants, eight were appointed to completely new posts, and eight consultants had renegotiated their job plans to create FTE/HTE posts in liaison psychiatry. Only three of the new posts were academic positions.

Table 1 also shows the number of higher training slots in liaison psychiatry for the different schemes in England, Scotland and Wales. Some schemes still have no training slot in liaison psychiatry although most are working hard to develop slots within the next year. Glasgow has plans to develop two (possibly three) training slots in liaison psychiatry and South Western is hoping to convert a senior house officer post into a specialist registrar training post in liaison psychiatry. Dundee has a HTE consultant in liaison psychiatry with plans to develop a liaison psychiatry training slot.

Some schemes have training slots in liaison psychiatry which are supervised by trainers who themselves have few formal sessions (if any) in liaison psychiatry. In Aberdeen and Wessex there are currently no consultants in FTE/HTE liaison posts, yet the schemes offer a training slot. Both the trainers in these two regions have an interest in liaison psychiatry and one is a recognised expert. It is to be hoped that the expansion in liaison psychiatry will continue so that trainers who are keen to provide a comprehensive training will be able to expand their sessional commitments in liaison psychiatry or the role of trainer can be passed on to a consultant in a FTE/HTE liaison post.

\section{Comment}

The current state of liaison psychiatry in England, Scotland and Wales falls well below

Table 1. Location of consultant posts in liaison psychiatry or consultants with designated sessions in liaison psychiatry and the number of training slots available on specialist registrar rotations

\begin{tabular}{llll}
\hline Location & $\begin{array}{l}\text { Consultants with any specified } \\
\text { sesstons in lialson }\end{array}$ & $\begin{array}{l}\text { Consultants with full-time or half- } \\
\text { time equivalent post in liaison }\end{array}$ & $\begin{array}{l}\text { Speciallst registrar } \\
\text { training slot }\end{array}$ \\
\hline Aberdeen & 0 & 0 & 1 \\
Dundee & 1 & 1 & 0 \\
Glasgow & 4 & 2 & 0 \\
Edinburgh & 6 & 4 & 3 \\
Northern & 8 & 0 & 0 \\
Yorkshire & 9 & 4 & 2 \\
North West & 8 & 4 & 2 \\
Mersey & 2 & 1 & 1 \\
Wales & 4 & 3 & 2 \\
Trent & 6 & 4 & 3 \\
West Midlands & 3 & 1 & 1 \\
Oxford & 5 & 3 & 1 \\
London & & & 4 \\
$\quad$ North Thames & 7 & 6 & 8 \\
South Thames & 15 & 9 & 1 \\
East Anglia & 1 & 1 & 1 \\
Wessex & 5 & 0 & 0 \\
South Western & 2 & 0 & \\
\hline
\end{tabular}


the College's recommended guidelines. Services are patchy and higher training in liaison psychiatry is unavailable in some parts of the country. There are, however, some encouraging signs. The number of consultant posts (FTE) HTE) in liaison psychiatry have increased since the last survey by Mayou and colleagues in 1990 and there appears to have been a dramatic expansion in the past two years. Many trainees like liaison psychiatry and a small number of half-time general psychiatry/liaison psychiatry posts are being developed by trusts who wish to attract good candidates. In addition, consultants who are interested in liaison psychiatry are renegotiating job plans to create liaison posts within the districts in which they work.

Liaison psychiatry has developed over the years from an academic base and many posts are based in teaching hospitals. There is evidence from this survey that the speciality is beginning to broaden its base and 13 of the new posts created in the past two years are nonacademic.

Although many higher training schemes offer special interest sessions in liaison psychiatry. there are still some schemes in the country where a full year's training slot in liaison psychiatry is unavailable. This is unacceptable. and a priority of such schemes should be the development of a training slot in liaison psychiatry. If expansion in liaison psychiatry is to continue, more training slots will be required. The number of new consultant posts that are created each year in liaison psychiatry is not a good indicator of how many senior registrar training slots are required as expansion is partly occurring through consultants already in general psychiatry posts renegotiating their contracts. Hence, the manpower figures underestimate the number of consultant posts in liaison psychiatry in the country. Accurate information is important as future planning of services and the development of posts on training schemes are influenced by the manpower figures.

It can be argued that the move of psychiatrists away from the district general hospital setting and into the community, together with the development of psychiatry/community trusts separate from general hospital trusts, has highlighted, in many areas, the need for a specific psychiatrist to provide treatment for patients in the general hospital. Some liaison psychiatrists are even employed by general hospital trusts as opposed to community psychiatric trusts.

It is possible that the recent growth in liaison psychiatry is a bubble that will soon burst as resources for mental illness are focused more and more on the 'severely mentally ill'. Many patients in the general hospital setting (e.g. patients with somatoform disorders) are as severely disabled as patients with schizophrenia. consume enormous amounts of health service resources, yet receive little in the way of psychological help. There is growing awareness from physicians and surgeons of the high prevalence of psychological disorder in the general medical setting and a demand for the development of better psychological services (Royal College of Physicians \& Royal College of Psychiatrists, 1995). There is also demand from general practitioners for the development of treatment services for patients with somatoform disorders in the community. It is likely that liaison psychiatry will continue to expand although posts may become less hospital based and more orientated towards providing links between primary and secondary care.

\section{References}

House A. \& Hodgson. G. (1994) Estimating needs and meeting demands. In Liaison Psychiatry: Defining Needs and Planning Services (eds S. Benjamin. A. House \& P. Jenkins), pp. 3-15. London: Gaskell.

mayou, R., Anderson, H., Feinmann, C., et al (1990) The present state of consultation and liaison psychiatry. Psychiatric Bulletin, 14, 321-325.

Royal College of Physicians and Royal College of PSYCHIATRISTS (1995) The Psychological Care of Medical Patients: Recognition of Need and Service Provision (Council Report CR35). London: Royal College of Physicians and Royal College of Psychiatrists.

RoYal College of PSYCHiATRISTS (1996) Annual Census for Psychiatric Staffing 1995 (Occasional Paper OP34). London: Royal College of Psychiatrists.

E. Guthrie, Senior Lecturer in Liaison Psychiatry. University of Manchester, School of Psychiatry and Behavioural Sciences, Rawnsley Building. Manchester Royal Infirmary, Oxford Road. Manchester M13 9WL 